\title{
IODP's Untapped Wealth: Multi-Parameter Logging of Legacy Core
}

\author{
by Melanie E. Holland, Peter J. Schultheiss, Robert M. Carter, \\ John A. Roberts, and Timothy J.G. Francis
}

Since 1968, the Deep-Sea Drilling Project (DSDP) and the Ocean Drilling Program (ODP) have recovered and stored approximately $300 \mathrm{~km}$ of core. Half of every core has been kept as an archive, normally only available for viewing. These archive half-cores are well suited for automated non-destructive geophysical measurements (core logging), including many parameters that provide essential data for reconstructing Earth's climatic history, such as high-resolution magnetic susceptibility, natural gamma spectroscopy, and UV/VIS/IR spectrophotometry.

We recently used a Geotek MSCL-XYZ core logger at the IODP West Coast Repository to log archive core halves recovered by the Glomar Challenger in 1983. The MSCL-XYZ system is specifically designed to allow multiparameter, non-destructive geophysical data to be collected easily at high spatial resolutions on up to nine split-core sections between reloading. This enables the machine to be loaded and run unattended for periods of many hours (including overnight and weekends), making it well suited for logging of archive core in a repository environment. The immediate goal was to obtain a high-resolution paleoclimate record for DSDP Site 594, east of New Zealand in the Southwest Pacific, but our underlying intention was to open up the vast reservoir of paleoclimate and other data that await extraction from well-preserved archive-half cores from the previous scientific ocean drilling programs, and now in IODP custody.

\section{New Data From Old DSDP Site 594}

We obtained complete data sets of natural gamma, magnetic susceptibility, spectral color and RGB digital line scan images from the top $150 \mathrm{~m}$ of the sediment column at DSDP Site 594 using the MSCL-XYZ (Fig. 1). This has provided high-resolution climatic data from cores where no core or downhole log data were previously available (Kennett et al., 1986). The cores show striking alternations of calcareous biopelagic and terrigenous muds that represent, respectively, warm interglacial and cold glacial conditions (Griggs et al., 1983; Nelson et al., 1993; Carter and Gammon, 2004), with typical sedimentation rates at Site 594 of $10 \mathrm{~cm} \mathrm{ky}^{-1}$ (biopelagic) and $16 \mathrm{~cm} \mathrm{ky}^{-1}$ (terrigenous; Kennett et al., 1986). Natural gamma was of primary interest and was collected at $5-\mathrm{cm}$ intervals (nominal resolution 300-500 yr). To our knowledge, this is the first time that a high-resolution natural gamma data log has been recovered from an archive core half. Magnetic susceptibility data and color spectrophotometer data were collected at $2-\mathrm{cm}$ intervals (nominal resolution 125-200 yr). Digital line-scan images provided integrated color reflectance data at $0.1-\mathrm{cm}$ spatial intervals, equating to a nominal resolution of 6-10 yr. The excellent quality of the spectral color and RGB image data, despite the ephemeral nature of these properties, is a testament to the core storage techniques employed over 21 years.

The new data collected with the MSCL-XYZ have confirmed the exceptional status of the climatic record from Site 594 through marine oxygen isotope Stages 1-5 (Schultheiss et al., 2004). we interpreted peaks in the magnetic susceptibility record to reflect the presence of sand-sized, ice-rafted terrigenous detritus (IRD). The variability in IRD records that exists between other Southern Ocean cores (Carter et al., 2002) is echoed in this record, which bolsters the lack of a regionally uniform pattern of IRD occurrence in the Southern Ocean during this period. The natural gamma ray record for Site 594 shows a strong half-precessional $(\sim 10 \mathrm{ky})$ rhythmicity that is mirrored to a lesser extent in the other data sets. This data set provides an atmospheric climate record that can now be compared with its companion marine benthic oxygen isotope record (Fig. 1). The gray-scale and color reflectance records serve as a detailed proxy for the amount of calcium carbonate present and, hence, for pelagic productivity and sea-surface temperature at Site 594. Rich detail in these records indicates that abrupt, episodic climate changes characterize the DSDP Site 594 record down to the millennial scale during both glacial and interglacial intervals. At the high resolution of the RGB scan, the Site 594 climate record is pervaded by short-term biopelagic/ terrigenous fluctuations equivalent to temperature changes of $\sim 0.2-1.0^{\circ} \mathrm{C}$ (Nelson et al., 1993) over periods of decades to centuries. These fluctuations are similar to those recorded in Earth-surface instrumental temperatures for the 19th and 20 th centuries.

\section{Reevaluating Repository Core}

Site 594 serves as an example of the wealth of data that remains within repository core. Many DSDP and even early ODP cores were obtained prior to the implementation of automated non-destructive core logging techniques; however, even recently obtained cores are not logged with all sensor systems at the high spatial resolutions desired for many studies due to the lack of available shipboard logging time. This is particularly true for techniques that require long measurement times (e.g., natural gamma) or 
techniques that can measure property changes at very small spatial intervals (e.g., magnetic susceptibility using a point sensor). If these data were routinely collected post-cruise at the core repository, then shipboard data collection time could be more effectively used.

This potential to return to repository core is particularly timely for two reasons. First, there will soon be a hiatus in regularly scheduled drilling expeditions with the riserless vessel. During the interval, scientists might formally propose IODP expeditions to core repositories to further examine cores, take samples, and integrate data from sites cored in the same area, though not necessarily on the same drilling leg. High-resolution, non-destructive testing with the MSCL-XYZ would complement such an effort. More urgently, as core working halves become depleted, pressure is mounting to allow subsampling from the archive core-halves. Once opened to sampling, portions (often the most interesting intervals!) of these continuous records are destroyed. The community now has the tools necessary to collect continuous geophysical data on ocean cores drilled over the past three decades.

\section{Opportunity in 2005 at U.S.-Based Core Repositories}

In the mid 2005, there will be a low-cost opportunity to collect multi-sensor core data from archive halves stored at the IODP West Coast Repository, La Jolla, Calif.; the Gulf Coast Repository, College Station, Tex.; and the East Coast Repository, Palisades, N.Y. The MSCL-XYZ system, with natural gamma, color spectrophotometry, magnetic susceptibility, RGB line-scan imaging, and possibly a new IR reflectance imaging spectroscopy sensor (spectra-map. co.uk), will travel to each of these repositories. Investigators are invited to suggest archive cores to be logged. Please contact Geotek (melanie@geotek.co.uk) if you are inter- ested in taking advantage of this opportunity to collect high-resolution data from any of your favorite sites.

\section{References}

Carter, L., Neil, H.L., and Northcote, L., 2002. Late Quaternary ice rafting events in the SW Pacific Ocean, off eastern New Zealand. Mar. Geol., 191:19-35.

Carter, R.M., and Gammon, P., 2004. New Zealand maritime glaciation: millennial-scale southern climate change since 3.9 Ma. Science, 304:1659-1662.

Kennett, J.P., von der Borch, C.C., et al., 1986. Init. Repts. DSDP 90: Washington, DC (U.S. Govt. Printing Office).

Griggs, G.B., Carter, L., Kennett, J.P., and Carter, R.M., 1983. Late Quaternary marine stratigraphy southeast of New Zealand. Geol. Soc. Am. Bull., 94:791-797.

Nelson, C.S., Cooke, P.J., Hendy, C.H., and Cuthbertson, A.M., 1993. Oceanographic and climatic changes over the past 160,000 years at Deep Sea Drilling Project Site 594 off southeastern New Zealand, Southwest Pacific Ocean. Paleoceanography, 8:435-458.

Schultheiss, P.J., Holland, M.E., Francis, T.J., Roberts, J.A., and Carter, R.M., 2004. Fulfilling the promise of the DSDP/ODP legacy with multi-parameter logging of archive cores. Eos, Trans. Am. Geophys. Union, 85(47): PP23B-1432. (Abstract)

\section{Authors}

Melanie E. Holland, Geotek Ltd, 3 Faraday Close, Daventry, NN11 8RD, U.K., e-mail: melanie@geotek.co.uk

Peter J. Schultheiss, Geotek Ltd, 3 Faraday Close, Daventry, NN11 8RD, U.K.

Robert M. Carter, Marine Geophysical Laboratory, James Cook University, Townsville, Qld. 4811, Australia

John A. Roberts, Geotek Ltd, 3 Faraday Close, Daventry, NN11 8RD, U.K.

Timothy J.G. Francis, Geotek Ltd, 3 Faraday Close, Daventry, NN11 8RD, U.K.

Figure 1. Core log data collected from DSDP Site 594 archivehalf cores in the summer of 2004. 